\title{
FACTORS OF DIGITALIZATION OF THE MARKETING ACTIVITY OF TOURIST ENTERPRISES OF UKRAINE IN THE CONDITIONS OF GLOBAL DIGITALIZATION
}

\author{
Marta Barna1, Iryna Melnyk², Rostyslav Baran³
}

\begin{abstract}
The main purpose of the article is to determine the main current trends and factors of digitalization of the tourism industry, which have a significant impact on the efficiency and increase the performance of economic entities in the tourism industry of Ukraine. The theoretical and methodological basis of the study consisted of the publications of the economists, who analyzed the problems of formation and prospects for the development of Internet marketing. A monographic method was used to cover the scientists' views on the research issue. Correlation and regression methods of analysis were tested in determining the factors of digitization. The article systematizes the dynamics of the development of the tourism industry and indicators of the economic activity of tourist enterprises in the global and national context. It is determined that due to the intensification of crises and quarantine measures caused by the spread of COVID-19, the number and expenditures of tourists on entertainment, the income of tourist enterprises, the number of people employed in the tourism industry have significantly decreased. At the same time, the process of digitalization of the studied industry has accelerated in terms of the growth of investments aimed at the development of marketing startups of a digitalization nature. The evolution of marketing approaches to the digitalization of tourism industry enterprises is theoretically comprehended. The main stages include traditional individual tour operators, e-business, e-commerce, smart tourism. It is concluded that domestic enterprises of the tourism industry lag significantly behind similar business entities in terms of the process of digitalization of economic processes and marketing mix. The factors of digitalization of the marketing activity of tourist enterprises are generalized. The results of factor analysis on the importance of using elements of digitalization in the marketing activities of tourism enterprises of Ukraine are analyzed and visualized. It is determined that the most significant influence on the effectiveness of marketing activities using elements of digitalization in the tourism industry of Ukraine is exerted by such factors as: chatbots based on artificial intelligence, voice search and voice control, virtual reality, augmented reality, internet of things, robots, contactless payments, cyber-security measures, recognition technology, large data sets, artificial intelligence.
\end{abstract}

Key words: Internet marketing, digitalization, tourist enterprises, tourism, globalization.

JEL Classification: M31, Z32, Z33

\section{Introduction}

The development of marketing activity and effective use of modern information technology is an integral part of the successful operation of tourist enterprises. The symbiosis of certain factors formed a basis for the emergence of a new direction of the modern concept of Internet marketing.

The need for people to travel faster, safer, and more efficiently has led to the emergence of breakthrough

\footnotetext{
Corresponding author:

${ }^{1}$ Lviv University of Trade and Economics, Ukraine.

E-mail: martabarna@ukr.net

ORCID: https://orcid.org/0000-0001-5248-9774

${ }^{2}$ Lviv University of Trade and Economics, Ukraine.

E-mail: gaveshta@gmail.com

ORCID: https://orcid.org/0000-0002-3132-6500

${ }^{3}$ Ivano-Frankivsk Educative and Research Institute of Management

of West Ukrainian National University, Ukraine.

E-mail: baranr32@gmail.com

ORCID: https://orcid.org/0000-0002-3275-489X
}

innovative solutions. In recent decades, the impact of technology on the travel industry has become even more appreciable due to the use of new IT services, which has led to a significant increase in the size of the online travel market and increased digitalization of the tourism industry.

On the other hand, the intensification of crises has increased the risks of the effective development and operation of certain industries. In general, the 
impact of the COVID-19 pandemic has brought some industries to the verge of bankruptcy (for example, hotel and restaurant establishments) and created the preconditions for a sharp jump and development of others (including the sector of information technology). Therefore, there is a need to analyze the statistics of international tourist flows for the last period, which can help understand general trends, identify factors of the digitalization of tourist enterprises and develop a strategy for further steps of the digitalization of the tourism industry in Ukraine in the conditions of global uncertainty. The purpose of the article is to determine the main current trends and factors of digitalization of the tourism industry, which have a significant impact on the efficiency and increase the performance of economic entities in the tourism industry of Ukraine.

\section{Literature review}

Several publications of the economists, who analyzed the problems of formation and prospects for the development of Internet marketing, have become a theoretical basis of the study. In particular, L. Weber (2009) emphasizes the need to introduce new ways of finding customers through social networks, which should create the conditions for the formation of a community of potential customers and maximize profits in the face of global uncertainty. P. Copley (2004) substantiates the conceptual approaches to the management of marketing communications in the context of the digitalization of society, while $\mathrm{X}$. Font and S. McCabe (2017) systematize the methodological principles of forming an Internet marketing system for tourist enterprises.

From a scientific point of view, the studies of O. Mulska, O. Levytska, V. Kutsyk (2020); T. Vasyltsiv, O. Klipkova, L. Lupak, N. Mitsenko, I. Mishchuk (2019); T. Vasyltsiv, R. Lupak, M. Kunytska-Iliash (2019) are noteworthy, in which the authors point to the leading role of the information and communication technology sector in the sustainable growth of the national economy and justify public policy measures in the context of the global digitalization of society and economy.

On the other hand, E. Matthnai (2019), Berlow, J., Stuart, P. (2007) in their works consider practical features of the use of marketing technologies while managing the tourist enterprise in the context of strengthening their digitalization. At the same time, the scientists did not pay attention to the issues related to the assessment of the factors of the digitalization of tourist enterprises, which in the conditions of COVID-19 have acquired a new sound and significance.

\section{Statistical data}

In general, it can be noted that the number of international tourists in 2020 amounted to 381 million people, which is $26 \%$ less than in 2019 and corresponds to the data fixed 30 years ago. The income of the travel and tourism industry in 2020 amounted to $348.8 \mathrm{bln}$ USD, which is $52 \%$ less than in the previous year. At the same time, the volume of the global market of tourist services in 2020 decreased from 1691 to 1541.0 bln USD (WTO, 2020). Such trends are associated with strict quarantine measures implemented in almost all countries of the world. However, as it can be seen in Figure 1, according to the forecast data of 2021, this figure is expected to be even exceeded as of 2019 to 1701.8 bln USD (positive dynamics based on the extrapolation of the trend is expected in 2022, provided other things being equal), which the authors first of all associate with the intensive use of tools for marketing activity digitalization in the tourism sector.

Continuing the analysis of the dynamics of the studied industry on a global scale, the authors note that at the beginning of 2021 the share of the world GDP due to constant restrictions on mobility was only $10.4 \%$, i.e., decreased by $5.5 \%$ in 2020 . An extremely negative consequence lay in the fact that in 2020, 62 million jobs were lost, which is $18.5 \%$ less than in the previous year. As a result, there are only 272 million employees left in the industry, compared to 334 million in 2019. The authors point out that the expenditures of domestic tourists decreased by $45 \%$, while international - by an unprecedented $69.4 \%$. The tourists' expenditures on entertainment decreased by $49.4 \%$, while the expenditures of business tourists decreased by as much as $61.0 \%$. Air carriers were also significantly affected. The number of flights operated by airlines globally in 2019 was 38.9 million, and in 2020, there was an unprecedented decline in this figure to 16.4 million (WTTC, 2020).

However, despite the significant losses in the world GDP described above, the tourism industry also received significant investments last year. Most of them were aimed at marketing startups based on the digitalization of processes. First of all, the authors mean the growth of the volume and number of virtual tours. In total, about 2.4 bln USD were invested in the travel and tourism industry, which, however, is $58.11 \%$ less than in 2019. Only in the first quarter of 2020, 1.4 bln USD were invested in the implementation of 57 startups in the field of tourism, almost all of which were associated with the digitalization of various processes (Foreign Direct Investment Statistics, 2020). The authors note that in search engines, the monthly search for virtual trips increased by 28.5 times - from 8,981 search queries per month in February 2020 to 25,661 in April of that year (Compare the Market, 2020). Besides, the size of the global market of virtual reality was estimated at 15.81 bln USD in 2020 and is expected to grow by another $30.9 \%$ by 2028 .

At today's stage of the development of the world society, it is clear that the global economy continues 


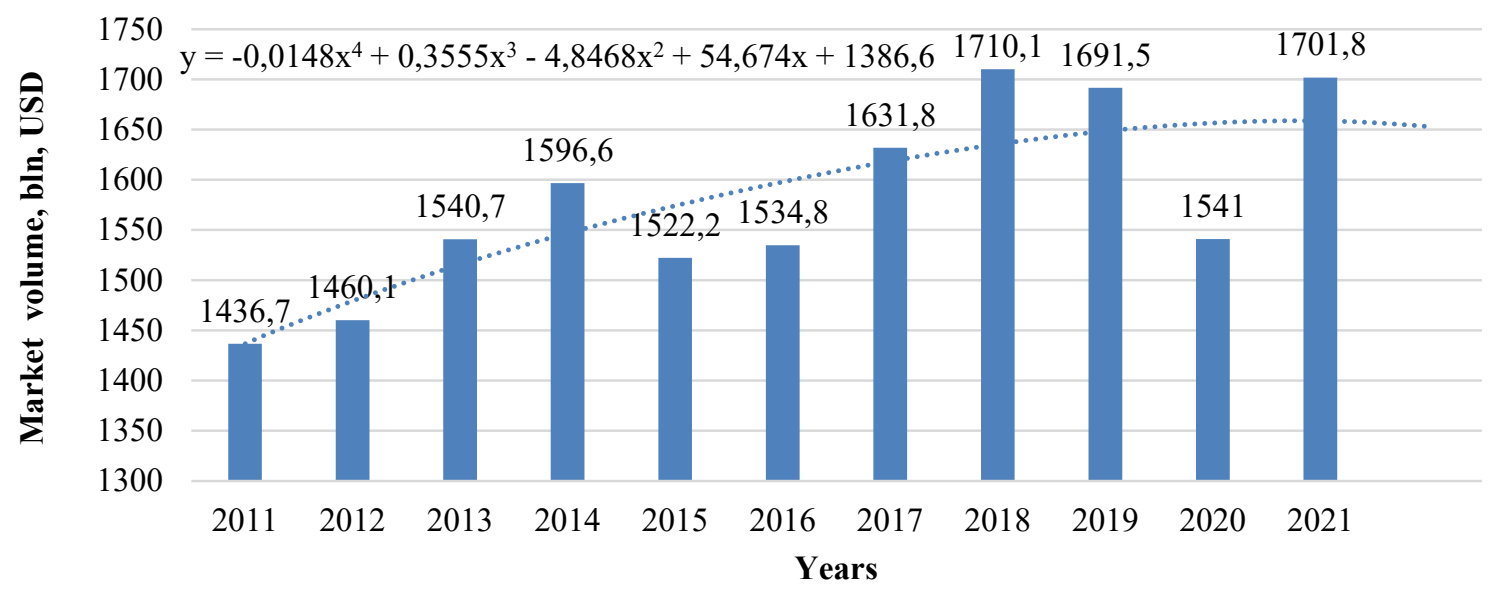

Figure 1. Dynamics of the volume of the global market of tourist services, bln USD, 2011-2022 (2021-2022 - forecast data) Source: based on WTTC

250

200

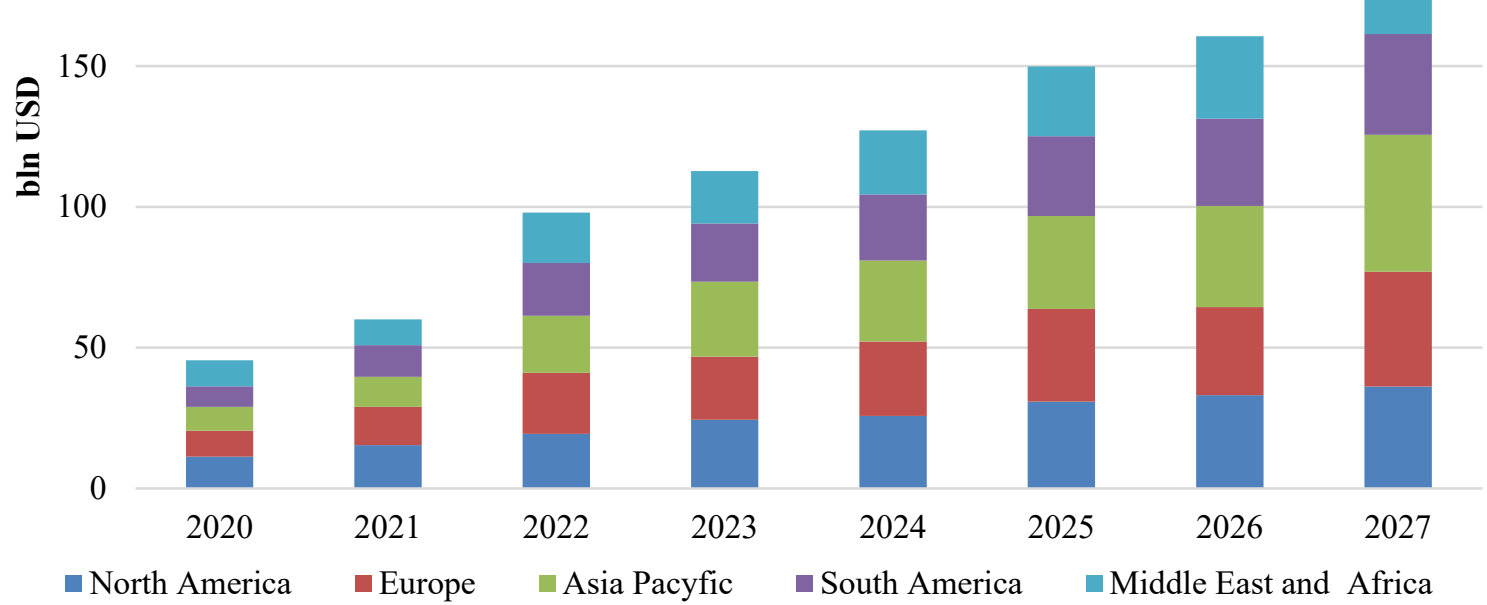

Figure 2. Dynamics of the volumes of the global market of virtual reality, 2020-2027 (2021-2027 - forecast data)

Source: based on Data Bridge

to digitalize intensively. This is caused first of all by the fact that a significant proportion of people work remotely and adhere to security measures on social distance, therefore the use of the Internet and similar networks has increased many times. Most businesses use online marketing technologies to increase their presence in global networks. Given this and other factors, the volume of digital marketing has grown. It should be noted that the average amount of time spent by potential consumers in digital networks was about 7 hours per day in 2020, i.e., twice as much as in 2019 (J. Brandon, 2020). At the same time, the daily time spent on social networks by Internet users worldwide in 2020 was 145 minutes.
The number of social media users increased by more than $10.5 \%$ (over 376 million people) in the period from July 2019 to July 2020, having reached 3.96 bln USD. In total, in 2020, more than 2 billion people purchased goods or services on the Internet. Moreover, for the same year, the volume of electronic retail trade exceeded 4.2 trillion USD worldwide (Daily Infographics, 2020).

Despite the initial decline in the global economy due to the pandemic, the expenditures on digital advertising increased by $12.2 \%$ compared to the previous year in the United States in 2020, having reached 139.8 bln USD per year. For example, in the United States in 2020, the income from advertising 
in social networks reached 41.5 bln USD, which accounts for almost $30 \%$ of all the income from online advertising. In the year under review, the expenditures on digital advertising in the tourism industry in the United States, according to the experts, reached 3.24 bln USD, which is $41.0 \%$ less than last year (CNBC, 2020).

Despite some destructive factors that affected the global economy last year, the tourism industry is finally showing signs of recovery. However, the long-awaited leap depends mainly on the pace of vaccination, the ease of travel restrictions, the favorable development of the global economy, the further digitalization of the tourism industry, and the resumption of air transport. The analysis of recent trends in the short term, which have a direct or indirect impact on the recovery of the tourism industry, gives grounds for the following conclusions. In 2020, more than 944 million doses of the coronavirus vaccine were introduced in 170 countries; in 2021 about 15.9 million vaccines are administered daily in the world. At this rate, it will take years to achieve a significant level of global immunity. However, this figure is growing steadily, and new vaccines are appearing in the market around the world (Bloomberg, 2021). However, unfortunately, in such conditions, $66 \%$ of all the destinations worldwide are fully or partially closed to international tourism (WTO, 2020).

According to the experts, domestic tourism is expected to fully recover under the most favorable conditions by the second half of 2022, which is 1-2 years ahead of similar trends on foreign travel. At the same time, the analysts also predict that the total income of the tourism industry will reach about $540 \mathrm{bln}$ USD in 2021 (approximately 54\% growth per year) (Bloomberg, 2021).

\section{Evolution of marketing approaches to digitalization}

Regarding marketing startups using digital technologies in the tourism industry, it is worth noting the following trends in the leading tourism brands. For example, the multinational company Kook, the world's leading travel and leisure booking platform, raised $200 \mathrm{mln}$ USD in this area in early 2021 (PR Newswire, 2021).

Thus, new opportunities through digital marketing in the tourism industry depend on the ability of tour operators to adapt their business to the current travel scenario in the context of digitalization. Historically, the digitalization of marketing activities both globally and in Ukraine has gone through the following main stages (Figure 3): (1) traditional individual tour operators (late 90s - early 2000s) - internal database, the low level of digitalization, and the use of computer technology; (2) e-business (2000-2009) - the creation of an e-business environment, an increase in the volume of Internet operations, the introduction of certain functions of Internet marketing; (3) e-commerce (2010-2018) an increase in the level of global interconnectedness and interdependence of tourism businesses, the introduction of innovations in global sales chains, the implementation of online strategies B2B, B2C, C2C; (4) smart tourism (2019-present) - the formation of smart visualization of the tourist product, contact with the customer online in real-time; the application of high technologies, including elements of Industry 4.0, the development of new innovative products, the formation of global chains of added value.

Due to this, the number of travel companies did not decrease even during the COVID-19 pandemic, including in Ukraine, as evidenced in particular by the dynamics of collective accommodation. Thus, in 2019 the mentioned indicator increased by 616 units compared to the previous year (from 4719 to 5335 units), even though the number of people who used the mentioned accommodation facilities decreased slightly - from 7006 thousand people in 2018 up to 6960 thousand.

Unfortunately, domestic tourism companies lag far behind similar businesses on the digitalization of business processes and marketing mix. However, in the digital agenda, the government has stated the need to promote the implementation of the principles of Industry 4.0, which will help to withstand fierce competition from enterprises in the industry, especially in the context of continuing certain quarantine restrictions because of COVID-19, which are global.

The authors note that, according to the experts, on a global scale, the digitalization of travel and tourism, in general, can bring the world economy and society more than 1 trillion USD of additional income directly or indirectly in the next decade (World Economic Forum, 2018). In addition, social benefits include saving costs and time for consumers and reducing environmental transaction costs.

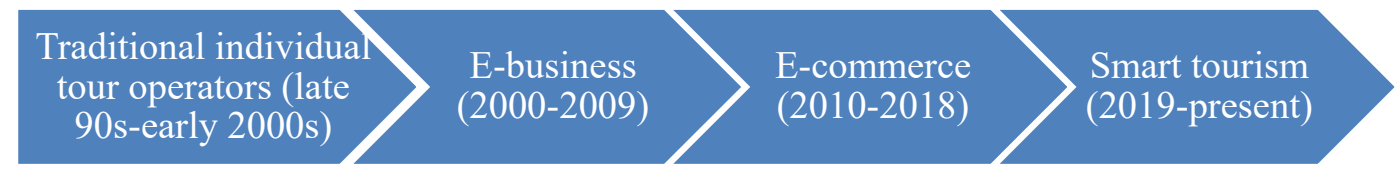

Figure 3. Global evolution of marketing approaches to the digitalization of tourist enterprises

Source: developed by the authors 
Table 1

Potential transactional income and benefits for society from the digitalization of the tourism industry at the global level in 2016-2025 (expert estimates)

\begin{tabular}{|c|c|c|c|c|}
\hline $\begin{array}{c}\text { Components } \\
\text { of the tourism industry / } \\
\text { sphere of influence }\end{array}$ & $\begin{array}{l}\text { Impact on business } \\
\text { (bln USD) }\end{array}$ & $\begin{array}{l}\text { Impact on the social sphere } \\
\text { (bln USD) }\end{array}$ & $\begin{array}{c}\text { Reduction of } \\
\text { harmful emissions } \\
\text { (bln USD) }\end{array}$ & $\begin{array}{l}\text { Impact on labor } \\
\text { resources (bln USD) }\end{array}$ \\
\hline Travel sector & 100 & 165 & - & 270 \\
\hline Tourist ecosystem & 105 & 380 & 170 & 940 \\
\hline High-tech enterprises & 190 & 20 & 143 & 100 \\
\hline Security and safety & 10 & 140 & - & 10 \\
\hline Total & 405 & 705 & 313 & 1320 \\
\hline
\end{tabular}

Source: based on World Economic Forum, 2018

\section{Factors of the digitalization of marketing activity of tourist enterprises}

Cloud technologies used to access, manage and store large databases on the Internet play an extremely important role among technological trends in the development of marketing of tourist enterprises. According to the 2020 survey, more than half of European travel agencies and tour operators purchased cloud technologies used via the Internet, while in 2016 only $29 \%$ used this practice. In addition, the global sociological survey of the travel services market conducted by the WTO in December 2020 showed a sharp increase in the use of chatbots in the travel and hospitality industry. At the same time, the majority of respondents (64.2\%) surveyed in Ukraine suggested that this type of software may also play a significant role in the future. This marketing tool is used mainly in the field of tourism to accumulate queries or bookings in realtime. It is also expected that virtual agents and chatbots will become one of the main services implemented or planned by airports around the world by 2022 .

As the coronavirus pandemic disrupted the organization and implementation of traditional travel, the interest in using the latest technologies and innovative solutions to restore travel and tourism has risen sharply since 2020 . For example, more than $58.4 \%$ of the respondents (consumers of travel services) support the introduction of digital passports of the vaccination from COVID-19 for international travel. The mentioned global WTO survey in 2020 showed that tourists from Thailand were most convinced of this need ( $74.1 \%$ of the respondents). In Ukraine, $49 \%$ of the respondents said that technology would be extremely important for global security during the COVID-19 pandemic. At the same time, German tourists were much more skeptical about this (only $23.5 \%$ of the respondents answered affirmatively). In terms of travel-enhancing technologies, according to the survey conducted in September 2020, mobile marketing applications that provide real-time information and travel alerts on pandemic aspects, as well as contactless payments (World Tourism Organization, 2021), are identified as important marketing tools.
It is clear that digital travel, or digital tourism, refers to the use of digital tools by travelers during the overall tourist experience. For example, booking travel products online can be considered part of this digital process. According to the data of the Statista Global Consumer Survey (2020), hotels, car rental, and rental tickets were among the main tourist products booked online in 2020. The number of hotel rooms and tickets booked online also increased significantly (by $38 \%$ compared to the previous year).

In addition to online booking, online travel directions, travel destinations, and food reviews have become another important aspect of the overall digital tourism experience. From 2014 to 2020, the total number of user reviews and opinions on Tripadvisor, one of the most famous travel websites, more than quadrupled. The tourist interest in posting and reading travel tips and comments on the Internet was confirmed by the fact that Tripadvisor was the most visited travel and tourism website in the world in January 2021 (Statista Global Consumer Survey, 2020).

At the present stage, social networking websites also play an important role in the tourism industry, as tourists use these platforms to share online content related to travel planning and trip implementation. Meanwhile, travel companies use them as a marketing tool, offering vacation spots and advertising travel products. According to the above study, approximately $31 \%$ of the Ukrainian travelers surveyed used social networks as a source of information for domestic travel planning (World Tourism Organization, 2021). As for social network profiles, National Geographic Travel has become the most popular source influencing the organization and promotion of travel on Instagram in the world as of May 2020 (Travel - National Geographic, 2020).

The authors note that due to the coronavirus pandemic, the income of one of the world's largest companies providing reservation services for hotels, apartments, cars, and air tickets - Booking Holdings worldwide decreased significantly in 2020 compared to the previous year. In 2019, the company's total income amounted to more than 15 bln USD, and in 2020 the 
income fell to about 6.8 bln USD. In total, Booking Holdings' net income worldwide was about $59 \mathrm{mln}$ USD in 2020, which is the lowest figure recorded since 2007. The income of one of the main competitors of Booking Holdings - Expedia in 2020 also decreased more than twice due to the crisis in the health care sector (Annual Reports and Proxies - Expedia Group, 2020).

Using the data of the global survey of tourists conducted by the WTO for Ukraine in 2019 and 2020 and the data of the authors' expert survey of the top managers of the tourist companies in western Ukraine based on factor analysis tools, the authors have outlined the factors that most influence the effectiveness of the use of elements of the digitalization of marketing mix in the tourism sector (Table 2).

\section{Conclusions}

The research results using factor analysis data suggest that the quarantine measures caused by COVID-19 have significantly accelerated the technological process of digitalization of marketing activity in the field of tourism, as social distancing and hygiene requirements and restrictions have forced consumers to use digital rather than personal offline services. The most significant impact on the effectiveness of marketing activity using the elements of digitalization in the tourism industry of Ukraine is exerted by such factors as:

1. Chatbots based on artificial intelligence have a significant impact on the effectiveness of marketing activity in the travel industry because with this technology customers can be provided with quick answers to their questions around the clock 7 days a week, regardless of staff availability. This can be important in the context of maximizing the needs of modern consumers of tourism services. As a rule, chatbots answer high-quality questions with standard answers. Modern chatbots are constantly being improved based on large-scale interaction. In addition, their use is extremely effective in counteracting the spread of the COVID-19 pandemic and global safety and hygiene measures.

2. Voice search and voice control. Smartphones, smart speakers, and assistant guides help increase the efficiency of voice search and improve technological solutions in the tourism industry. In particular, more and more travel customers are using voice search to book tickets, hotel rooms, and choose tourist destinations and general travel arrangements. Therefore, travel companies need to develop their website based on voice search to increase the profitability of marketing activity.

Moreover, the voice menu also plays an increasingly important role in the real (physical) travel experience. In a hotel room, voice-controlled devices can be used to control lighting and heating in rooms or to obtain tourist information without having to talk to the staff. This technology is also important for socially disabled people.

3. Virtual reality. Virtual reality has become a new widespread technology in many different sectors, but its role in the tourism industry is particularly important because it allows tourists to emotionally experience physically remote places (tourist destinations) without leaving their home, and may eventually become a stimulus to booking a visualized tour, hotel room, car, etc.

With the help of tours using virtual reality technology, customers can experience everything from virtual tours of hotels and restaurants to attractions, national parks, or even certain types of tourist activities. Interactivity and immersion of the client in the tourist product can also help provide the company with competitive advantages in the market through a significant expansion of the potential target audience of consumers. Most

Table 2

Results of factor analysis on the importance of the implementation of elements of digitalization in the marketing activity of tourist enterprises of Ukraine 2019-2021

\begin{tabular}{|l|c|c|c|c|}
\hline \multirow{2}{*}{\multicolumn{1}{c}{ Factors of digitalization }} & \multicolumn{4}{c|}{ Resulting variables } \\
\cline { 2 - 5 } & Competitiveness & Sales volumes & Consolidated returns & $\begin{array}{c}\text { Ranking position } \\
\text { of the tour operators }\end{array}$ \\
\hline Voice search and voice control & $0.843^{*}$ & 0.643 & 0.621 & 0.932 \\
\hline Robots & 0.573 & 0.512 & 0.670 & 0.809 \\
\hline Contactless payments & 0.642 & 0.932 & 0.956 & 0.816 \\
\hline Virtual reality & 0.896 & 0.416 & 0.512 & 0.765 \\
\hline Chat bots & 0.734 & 0.824 & 0.781 & 0.967 \\
\hline Cyber-security measures & 0.794 & 0.513 & 0.698 & 0.747 \\
\hline Internet of things & 0.698 & 0.738 & 0.613 & 0.744 \\
\hline Augmented reality & 0.548 & 0.573 & 0.598 & 0.839 \\
\hline Artificial intelligence & 0.486 & 0.610 & 0.714 & 0.567 \\
\hline Large data sets & 0.654 & 0.791 & 0.683 & 0.412 \\
\hline
\end{tabular}

${ }^{*}$ Note: Factors affecting at the level $>0.642$ are highlighted in bold

Source: based on the results of the authors' calculations and expert assessments. 
tours of this type today are compatible with major browsers, which also increase the efficiency of marketing services in the industry.

4. Augmented reality. Augmented reality is similar to virtual, but involves increasing the real environment of people, not replacing them. One of the main advantages of this particular technological trend is that it is cheaper than the virtual one, as users only need a smartphone or other smart devices with Internet access to receive the relevant information and use the virtual product.

With graphical additions, travel agencies can significantly improve customer engagement by providing consumers with valuable information or even exceptional entertainment. For example, applications can allow photos to be supplemented with a variety of filters and effects, and detailed features of local travel destinations can be displayed when customers point their smartphone at them, providing information at a specific time when it is most relevant to customers.

5. Internet of Things (IP). One of the most interesting trends in the spread of travel technology is the Internet of things, which involves the interconnection of everyday devices over the Internet, as well as allows them to send and receive certain data. For example, the IP technology can be used in a hotel room to provide customers with a device that connects to everything from lights, heaters, and air conditioners to automatically closing doors and using plumbing that allows to control all components from one place or via mobile devices. In addition, for example, many airports already have luggage storage facilities equipped with sensors that alert passengers when they pass their luggage.

6. Robots. Robotics technology is one of the most exciting forms of tourism technology, which is also constantly improving. For example, in hotels, robots are used as concierges to help meet new guests and provide comprehensive information on the check-in. In some hotels, they are used for cleaning and baggage handling.

In some restaurants, robots prepare and serve food. At airports, they are used to detect weapons and other potentially dangerous items. Moreover, some travel agencies use robots to pre-communicate with customers, increasing the efficiency of waiting time for customers. Like in many other technological trends in travel, the use of robots has increased significantly in response to the spread of COVID-19, as they have the potential to reduce human contact, which in no way threatens robots in operation.

7. Contactless payments. Another important form of travel marketing technology is the ability to accept contactless payments, which allow travel companies to process financial flows much faster, including in situations where customers do not have access to cash or their credit or debit card. This improves the interaction with customers, as it significantly saves time for both parties.

The use of contactless financial technologies is a key component of the marketing mix after the spread of the coronavirus pandemic and in the conditions of the reluctance of a significant proportion of customers to use cash due to the risk of spread of viral infections and other biological threats. The use of contactless payments also allows to increase the level of security of the enterprise's staff.

8. Cyber-security measures. Cyber-security is one of the key areas in the operation of tourist enterprises, which have a substantial database of customers. The biggest threats in this context include "phishing attacks" and "cyber-terrorist attacks". To successfully combat these destructive phenomena, tourist companies need to invest heavily in training staff on cyber-security issues and a variety of hardware and software solutions to strengthen the economic security and cyber-security of the enterprise. However, the analytical and legal departments of companies need to monitor changes in the regulatory and legal framework in the field of personal data protection of customers.

9. Recognition technology. Recognition technology is particularly interesting in the context of key technological trends due to its potential to remove barriers to customer interaction and the purchase and use of travel goods and services. The technology itself involves fingerprint recognition, face recognition, retinal scanning, and various other biometric identifiers.

This technology is already used in some hotels to allow access to rooms or check-outs with fingerprints. In the future, it is also expected that this technology will allow customers to pay for food by going through a special identification framework.

10. Large data sets. In modern tourism management, large databases are commonplace, and almost all successful companies use their data collection methods. One of the most effective applications of this data is to improve personalization when travel companies use the information which they accumulate to make certain adjustments to their travel products. Another important area of using primary and secondary databases is the analysis of current business activity. Financial managers of travel agencies can use large data sets to manage income, using the dynamics of key indicators of travel agencies' performance. They are also used to develop marketing strategies, including the optimization of pricing and promotional policies.

11. Artificial intelligence. In addition to robotics, artificial intelligence is used in other areas of marketing and other activities of the tourism industry as a means of digitalization and improving the efficiency of the enterprise. 


\section{References:}

Copley, P. (2004). Marketing communications management: concepts and theories, cases and practices. Amsterdam; London: Elsevier Butterworth-Heinemann.

Font, X., \& McCabe, S. (2017). Sustainability and marketing in tourism: its contexts, paradoxes, approaches, challenges and potential. Journal of Sustainable Tourism, 25(7), 869-883.

Mulska, O. P., Levytska, O. O., \& Kutsyk, V. I. (2020). State policy of maintaining the innovative forms of employment in the context of the economy digitalization. Regional Economy, 97(3), 81-90.

Vasyltsiv, T. G., Lupak, R. L., \& Kunytska-Iliash, M. V. (2019). Social Security of Ukraine and the EU: aspects of convergence and improvement of migration policy. Baltic Journal of Economic Studies, 5(4), 50-58.

Vasyltsiv, T. G., Klipkova, O. I., Lupak, R. L., Mitsenko, N. H., \& Mishchuk, I. P. (2019). Monetary and financial policy of Ukraine: theoretical-empirical connections and priorities of state regulation. Financial and Credit Activity: Problems of Theory and Practice, 4(31), 320-330.

Weber, L. (2009). Marketing to the Social Web: How Digital Customer Communities Build Your Business. John Wiley \& Sons.

Matthnai, E. (2019). Practical of the Use of Marketing Technologies in the Management of a Tourism Enterpise. Scientific Bulletin of Kherson State University: Series Economic Sciences, 35, 44-50.

Berlow, J., \& Stuart, P. (2007). Brand-oriented service. New competitive advantage. Moscow.

World Tourism Organization (2021). Retrieved June 2, 2021 from https://www.unwto.org/unwto-tourismdashboard

World Travel \& Tourism Council (2021). Retrieved June 6, 2021 from https://wttc.org

Foreign Direct Investment Statistics: Data, Analysis and Forecasts. Retrieved June 4, 2021 from: https://www.oecd.org/investment/statistics.htm

Compare the Market / Keep Life Simples. Retrieved June 4, 2021 from https: / / www.comparethemarket.com

Data Bridge. Retrieved June 10, 2021 from: https://www.databridgemarketresearch.com/reports/global-virtualreality-market

Brandon, John (2020, November 17). New Survey Says We're Spending 7 Hours Per Day Consuming Online Media. Forbes. Retrieved from www.forbes.com/sites/johnbbrandon/2020/11/17/new-survey-says-were-spending-7hours-per-day-consuming-online-media/ $\mathrm{sh}=181 \mathrm{a} 2 \mathrm{f5} 16 \mathrm{~b} 46$

Daily Infographics. Retrieved June 7, 2021 from https://www.statista.com/chartoftheday

CNBC: Stock Markets, Business News, Financials, Earnings. Retrieved June 3, 2021 from https://www.cnbc.com

Bloomberg. Retrieved June 9, 2021 from https://www.bloomberg.com/graphics/covid-vaccine-tracker-globaldistribution

PR Newswire: press release distribution, targeting, monitoring. Retrieved June 7, 2021 from https://www.prnewswire.com

Report of World Economic Forum (2018). Digital Transformation Initiative in collaboration with Accenture. Retrieved June 1, 2021 from http://reports.weforum.org/digital-transformation/wp-content/blogs.dir/94/mp/ files/pages/files/dti-executive-summary-20180510.pdf

Global Consumer Survey 2020. Retrieved May 25, 2021 from https://www.statista.com/news/global-consumersurvey-2020/en

Travel - National Geographic. Retrieved May 31, 2021 from https://www.nationalgeographic.com/travel Annual Reports and Proxies - Expedia Group. Retrieved June 8, 2021 from https://www.expediagroup.com/ investors/financial-information/annual-reports/default.aspx 